\title{
Levantamento quantitativo de microrganismos solubilizadores de fosfatos na rizosfera de gramíneas e leguminosas forrageiras na Amazônia
}

\author{
R. Sylvester-Bradley('); N. Asakawa $\left({ }^{2}\right) ;$ S. La Torraca $\left({ }^{2}\right) ;$ F.M.M. Magalhães $\left({ }^{2}\right)$; L.A. Oliveira $\left({ }^{2}\right)$ e R.M. Pereira( $\left.{ }^{3}\right)$
}

\begin{abstract}
Resumo
Após a escolha de um meio de enriquecimento seletivo a um maior número de microrganismos solubilizadores de fosfatos, foi feito um levantamento quantitativo dessas bactérias na rizosfera de Brachiaria decumbens, B. humidicola; Andropogon gayanus, Paspalum plicatum, Hyparrhenia rufa, Panicum maximum, Desmodium ovalifolium, Pueraria phaseoloides, Zornia sp. Stylosanthes capitata, S. guianensis (CIAT 136) e S. guianensis (IRI 1022), adubadas e não adubadas. De um modo geral, números maiores de bactérias solubilizadoras de fosfatos (superior a $1 \times 10^{7} / \mathrm{g}$ rizosfera) ocorreram na rizosfera de leguminosas, adubadas e não adubadas, e os números mais baixos nas gramíneas (inferior a $1 \times 10^{7} / \mathrm{g}$ rizosfera), com exceçăo de $\mathbf{H}$. rufa e P. maximum, sem adubação. De todas as forrageiras analisadas, a rizosfera de Zornia sp. adubada, foi a que melhor se apresentou tanto em número quanto em porcentagem de bactérias solubilizadoras. $\mathrm{O}$ número total de microrganismos foi maior nos tratamentos não adubados para todas as gramíneas analisadas e maior nos tratamentos adubados para todas as leguminosas com exceção de S. capitata. Os fungos solubilizadores de fosfatos, não foram considerados, uma vez que estavam presentes em quantidades bem pequenas.
\end{abstract}

\section{INTRODUÇÃo}

A produtividade vegetal nos trópicos é freqüentemente limitada pelos baixos níveis de nutrientes presentes nos solos em formas assimiláveis. Entre os nutrientes, o fósforo é talvez o fator mais limitante ao desenvolvimento vegetal nestas regiões, face a sua característica de alta estabilidade e, conseqüentemente baixa solubilidade especialmente nos oxissolos e ultissolos, que são as classes de solos de distribuição mais ampla nos trópicos (Fassbender, 1975; Kamprath, 1977). No entanto, uma parcela importante da população microbiana edáfica possui a habilidade de mineralizar fosfatos orgânicos e solubilizar fostatos inorgânicos, permitindo a liberação de
$\left(\mathrm{H}_{2} \mathrm{PO}_{4}\right)$ - diretamente assimilável pelas plantas (Epstein, 1975). Essa solubilização de fosfatos ocorre pela ação de ácidos orgânicos, inorgâ. nicos e $\mathrm{CO}_{2}$, produzidos nos processos normais do metabolismo de bactérias e fungos (Tardieux-Roche, 1966), que habitam principalmente a rizosfera das plantas (Sperber, 1958).

Em certos países, como os da União das Repúblicas Socialistas Soviéticas, a inoculação de microrganismos solubilizadores nas sementes tem sido usada extensivamente para proporcionar um melhor rendimento do plantio (Barea, 1979). No entanto, ainda não se sabe se o efeito positivo dessa inoculação é diretamente devido à solubilização de fósforo (Brown, 1974; Barea et al., 1976). Esses autores sugerem que a produção de fito-hormônios pelas bactérias inoculadas poderia estimular o crescimento das raízes que então, absorvem mais fósforo. Greaves \& Webley (1975), mostraram que noventa por cento da população das bactérias associadas às raízes de gramíneas forrageiras possuem fosfatase. Neste caso, não seria provável um efeito positivo de inoculação sobre a absorção de fósforo. No entanto, esses trabalhos foram realizados principalmente na forma de fosfato tricálcico, enquanto que em solos ácidos como os da Amazônia ocorrem os fosfatos fixados na forma de alumínio e ferro.

É importante estudar o papel dos microrganismos solubilizadores de fosfatos nos solos ácidos da Amazônia, não só para a melhor compreensão dos mecanismos envolvidos na interação solo-planta, como também pelas possibilidades que esses estudos abrem em torno da economia de adubos fosfatados solúveis comumente usados, com a introduçấo de fosfatos insoiúveis.

(1) - CIAT, Cali, Colômbia.

(2) - Instituto Nacional de Pesquisas da Amazônia, Manaus.

(3) - Fundação Universidade do Amazonas, Manaus. 
Com esse trabalho pretendemos iniciar estudos nesse sentido através do levantamento da microflora presente na rizosfera de gramíneas e leguminosas forrageiras e a freqüência de bactérias e fungos solubilizadores nessas populações microbianas. Para obter-se um meio seletivo a um maior número de microrganismos solubilizadores de fosfatos, foi feito inicialmente experimento com diferentes meios de enriquecimento. A escolha de fonte de carbono foi feita após a avaliação de metabolismos acidificante de culturas puras de bactérias e fungos solubilizadores em diferentes fontes de carbono.

\section{MATERIAIS E MÉTodos}

EXPERTMENTO I - Avaliação do metabolismo acidificante de culturas puras de bactérias e fungos solubilizadores de fosfato em diferentes fontes de carbono.

As culturas puras de bactérias e fungos foram isoladas de solo e de rizosfera de Brachiaria humidicola (quicuio da Amazônia), por diluições em placas com meio Basal (Ramos et al., 1968).

Uma alça de platina das culturas puras foi inoculada em meio líquido, em tubos de ensaio $(25 \mathrm{ml})$ contendo para 1 litro de água destilada: $2 \mathrm{ml} \mathrm{MgSO}{ }_{4} \cdot 7 \mathrm{H}_{2} \mathrm{O}(10 \%) ; 2 \mathrm{ml} \mathrm{CaCl}_{2}$ (1\%); $1 \mathrm{ml} \mathrm{NaCl}(10 \%) ; 4 \mathrm{ml} \mathrm{Fe}$ EDTA $(1,64 \%)$; $0,1 \mathrm{~g} \mathrm{KNO}_{3} ; 0,005 \%$ levedura; $2 \mathrm{ml}$ solução de micronutrientes $\left(0,2 \mathrm{~g} \mathrm{Ca}_{2} \mathrm{MoO}_{4} .2 \mathrm{H}_{2} 0 ; 0,235 \mathrm{~g}\right.$ $\mathrm{Mn} \mathrm{SO} \mathrm{H}_{4} \mathrm{H}_{2} \mathrm{O} ; 0,28 \mathrm{~g} \mathrm{H}_{3} \mathrm{BO}_{3} ; 0,008 \mathrm{~g} \mathrm{CuSO}_{4}$. $5 \mathrm{H}_{2} \mathrm{O} ; 0,024 \mathrm{~g} \mathrm{Zn} \mathrm{SO}$. $7 \mathrm{H}_{2} \mathrm{O}$, em $200 \mathrm{ml}$ de $\mathrm{H}_{2} \mathrm{O}$ destilada). Após a autoclavagem do meio foram acrescentadas $0,2 \mathrm{~g}$ de fosfato de rocha (catalão). As fontes de carbono testadas foram: glicose, malato, arabinose, succinato, glicerol e manitol, colocando-se $5 \mathrm{~g}$ por litro de meio (esterilizada separadamente). $\mathrm{O}$ pH inicial do meio foi acertado para 6,8 a 7,0 . Foram testadas três culturas puras de bactérias e três de fungos, com 3 repetições. A avaliação foi feita após 7 dias de incubação aeróbica em $30^{\circ} \mathrm{C}$ através do $\mathrm{pH}$ dos meios.

EXPERIMENTo"II - Seleção de mieios de cultura para microrganismos solubilizadores de fosfatos.
Foram testados quatro diferentes meios de cultura com as seguintes composições para 1 litro de água destilada:

Meio GL: $10 \mathrm{~g}$ glicose; $2 \mathrm{~g}$ extrato de levedura (Difco); $15 \mathrm{~g}$ agar.

Meio GES: $10 \mathrm{~g}$ glicose; $100 \mathrm{ml}$ extrato de solo; sais de base. (2 $\mathrm{ml} \mathrm{Mg} \mathrm{SO}(10 \%) ; 2 \mathrm{ml}$ $\mathrm{CaCl}_{2}(1 \%) ; 1 \mathrm{ml} \mathrm{NaCl}(10 \%) ; 2 \mathrm{ml}$ solução micronutrientes (a mesma usada no Experimento I; $4 \mathrm{ml} \mathrm{Fe} \mathrm{EDTA} \mathrm{(1,64 \% );} \mathrm{0,1} \mathrm{g} \mathrm{KNO}_{3}$ ); $15 \mathrm{~g}$ agar.

Meio GAGES: $10 \mathrm{~g}$ glicose; $5 \mathrm{~g}$ arabinose; $4 \mathrm{ml}$ glicerol; $100 \mathrm{ml}$ extrato de solo; sais de base; $15 \mathrm{~g}$ agar.

Meio GELP: $10 \mathrm{~g}$ glicose; $5 \mathrm{~g}$ peptona; $0,05 \mathrm{~g}$ levedura; $100 \mathrm{ml}$ extrato de solo; sais de base; $15 \mathrm{~g}$ agar.

Depois de autoclavados, foram colocados em cada meio, $50 \mathrm{ml} \mathrm{K} \mathrm{HPO}_{4}(10 \%)$ e $100 \mathrm{ml}$ $\mathrm{CaCl}_{2}(10 \%)$ (esterilizados separadamente), para produzir um precipitado de fosfato inorgânico, $\mathrm{CaHPO}_{4}$ (Katznelson \& Bose, 1959).

Foram testados juntamente o efeito de rosa-bengala (fungicida que inibe o crescimento radial de fungos) na concentração de $0,03 \mathrm{~g} / \mathrm{li}$. tro e também o efeito de $\mathrm{pH}$ ácido e neutro no crescimento dos microrganismos.

Contagem de microrganismos solubilizadores de fosfato nesses diferenies meios foi feita da rizosfera de Brachiaria humidicola de solo não adubado, coletada no Distrito Agropecuário - EMBRAPA, estrada Manaus-Caracaraí-Km 60. Foi considerado rizosfera o solo aderente às raízes. Amostra de 1 grama de rizosfera foi misturada em $9 \mathrm{ml}$ de solução salina $(1 \%)$, seguindo-se o método das diluiçñes sucessivas. De cada diluição foram transferidas alíquotas de $0,1 \mathrm{ml}$ para placas estére:s, acrescentando-se logo em seguida, os meios mantidos à temperatura de $45^{\circ} \mathrm{C}$ e mistuados imediatamente. (Método Pour-Plate). Foram feitas 3 repetições para cada diluição.

O número de bactérias e fungos solubilizadores assim como o total de microrganismos que cresceram nas p'acas, foi determinado pelo método de NMP (número mais provável - tabela de Mc. Grady), após uma semana de incubação à temperatura de $30^{\circ} \mathrm{C}$. $\mathrm{O}_{3}$ microrganismos solubilizadores formavam em 
torno de si um halo claro facilmente visível por contraste com o meio opaco (Ramos et al., 1968).

EXPERIMENTO III - Contagem de microrganismos solubilizadores no solo, na rizosfera e na raiz de Brachiaria humidicola.

Amostras de $B$. humidicola foram coletadas no mesmo local do Experimento anterior. $\mathrm{O}$ solo foi coletado à pouca distância das plantas e as raízes, após a remoção do solo foram lavadas em água estéril no laboratório.

A contagem total de microrganismos assim como o de solubilizadores seguiu a mesma metodologia descrita no Experimento II. O meio de enriquecimento utilizado para o crescimento foi o GES e o GL, ambos em pH neutro.

EXPERIMENTO IV - Levantamento quantitativo de bactérias solubilizadoras de fosfatos.

O levantamento foi feito em rizosfera de gramíneas e de leguminosas do Ensaio Regio. nal PROPASTO/CIAT, localizada ra Fazenda Mil Madeireira, Rodovia Manaus-Itacoatiara, $\mathrm{Km} 230$.

As gramíneas utilizadas foram: Paspalum plicatum, Hyparrhenia rufa, Panicum maximum, Brachiaria decumbens, Brachiaria humidicola e Andropogon gayanus; as leguminosas foram: Stylosanthes capitata, Stylosanthes guianensis (IRI 1022 e CIAT 136), Desmodium ovalifolium, Pueraria phaseoloides e Zornia sp.

As amostras de raízes foram coletadas, tanto das parcelas adubadas quarito das não adubadas com $50 \mathrm{~kg} \mathrm{P}_{2} \mathrm{O}_{5} / \mathrm{ha}$, correspondente a $150 \mathrm{~g}$ de superfosfato simples e $111 \mathrm{~g}$ de hiperfosfato por meia parcela $(4 \mathrm{~m} \times 3 \mathrm{~m})$. A rizosfera dessas plantas foi obtida agitando-se $5 \mathrm{~g}$ de sistema radicular coletado com o solo aderente em $50 \mathrm{ml}$ de solução salina contida em erlenmeyer de $125 \mathrm{ml}$. Após serem agitadas vigorosamente por 2 minutos, as raízes foram removidas e $1 \mathrm{ml}$ da solução de rizosfera foi diluída em $9 \mathrm{ml}$ de solução salina, procedeñdo-se então o método tradicional de diluição em série. O método de contagem seguiu o mesmo processo descrito no Experimento II.
O meio utilizado foi o GES, uma vez que não inibiu o crescimento de fungos e permitiu o melhor desenvolvimento das bactérias solubilizadoras.

\section{Resultados}

As três culturas de fungo acidificaram bem o meio com glicerol e glicose mas uma vez que todas as culturas de bactérias e de fungos acidificaram o meio contendo glicose (Tabela 1), esta fonte foi escolhida como constituinte de diferentes meios de enriquecimento, apesar de a solubilização de fosfatos não estar correlacionada unicamente com a produção de ácidos por microrganismos do solo (Sperber, 1958).

TABELA 1 - Medidas de $\mathrm{pH}$ de culturas de bactérias e fungos solubilizadores de fosfato em diferentes fontes de carbono. (Média de 3 repetiçōes)

\begin{tabular}{lcccccccc}
\hline \multirow{2}{*}{ Fonte de Carbono } & \multicolumn{3}{c}{ Bactérias } & \multicolumn{3}{c}{ Fungos } \\
& \multicolumn{1}{c}{$\mathbf{1}$} & $\mathbf{2}$ & $\mathbf{3}$ & $\mathbf{1}$ & $\mathbf{2}$ & $\mathbf{3}$ \\
& 3,1 & 3,5 & 3,6 & 2,7 & 3,6 & 3,5 \\
Glicose & 6,1 & 6,7 & 6,5 & 6,1 & 4,1 & 5,3 \\
Manitol & 8,5 & 8,4 & 8,7 & 8,4 & 8,3 & 3,7 \\
Malato & 8,5 & 8,6 & 8,8 & 7,7 & 7,5 & 8,7 \\
Succinato & 6,8 & 7,0 & 6,7 & 2,9 & 3,2 & 4,4 \\
Glicerol & 5,5 & 6,0 & 5,9 & 6,0 & 6,1 & 5,6 \\
Arabinose & & & & & &
\end{tabular}

De todos os meios testados, o meio GES apresentou um número maior de bactérias solubilizadoras. O número de bactérias solubilizadoras variou em torno de $10^{2}$ células $/ \mathrm{g}$ peso seco de rizosfera em todos os meios, principalmente em pH neutro (Tabela 2). Apesar de os fungos estarem presentes como microrganismo total, o número de fungos solubilizadores foi bem menor em relação às bactérias, em todos os meios, tanto em $\mathrm{pH}$ ácido quanto em pH neutro, assim como na presença ou ausência de rosa-bengala. 
TABELA 2 - Número total de microrganismos e de solubilizaćores de fosfatos em diferentes meios de enriquecimento (rizosfera de B. humidicola)

\begin{tabular}{|c|c|c|c|c|}
\hline \multirow[b]{2}{*}{$\begin{array}{c}\text { Meios de } \\
\text { Enriquecimento }\end{array}$} & \multicolumn{2}{|c|}{$\mathrm{pH}$ Ácido } & \multicolumn{2}{|c|}{$\mathrm{pH}$ Neutro } \\
\hline & $\begin{array}{c}\begin{array}{c}\text { Microrganismos } \\
\text { total }\end{array} \\
\mathrm{N} .{ }^{\circ} \times 10^{3} \times \text { g.p.seco-1 }\end{array}$ & \begin{tabular}{cc}
\multicolumn{2}{c}{ Solubilizadores } \\
Bact. $\quad$ Fungos \\
$\mathrm{N} .{ }^{\circ} \times 10^{2} \times$ g.p.seco-1
\end{tabular} & $\begin{array}{c}\begin{array}{c}\text { Microrganismos } \\
\text { total }\end{array} \\
\mathrm{N} .{ }^{\circ} \times 10^{3} \times \text { g.p.seco-1 }\end{array}$ & $\begin{array}{c}\text { Solubilizadores } \\
\text { Bact. Fungos } \\
\mathrm{N} . \times 10^{2} \times \text { g.p.seco- }{ }^{-1}\end{array}$ \\
\hline $\mathrm{GL}$ & 450 & 0 & 95000 & 40 \\
\hline GES & 950 & 30 & 4500 & 250 \\
\hline GAGES & 250 & 0 & 75000 & 9 \\
\hline GELP & 450 & 15 & 35000 & 11 \\
\hline $\mathrm{GL}$ + rosa bengala & 250 & 0 & 11500 & 9 \\
\hline GES + rosa bengala & 700 & 0 & 14000 & 150 \\
\hline GAGES + rosa bengala & 250 & 0 & 7500 & 0 \\
\hline GELP + rosa bengala & 450 & 3 & 11000 & 75 \\
\hline
\end{tabular}

A contagem feita no solo, na rizosfera e na raiz de $B$. humidicola, mostrou uma maior ocorrência tanto de microrganismo total como a de bactérias solubilizadoras de fosfato na rizosfera, e o meio GES foi o mais eficiente para o crescimento de bactérias solubilizadoras (Tabela 3). Novamente, o número de fungos solubilizadores foi bem menor que o de bactérias, mas, estavam presentes principalmente no meio GL.

TABELA 3 - Número total de microrganismos e bactérias solubilizadoras de fosfato no solo, rizosfera e raiz de B. humidicola em 2 meios de enriquecimento

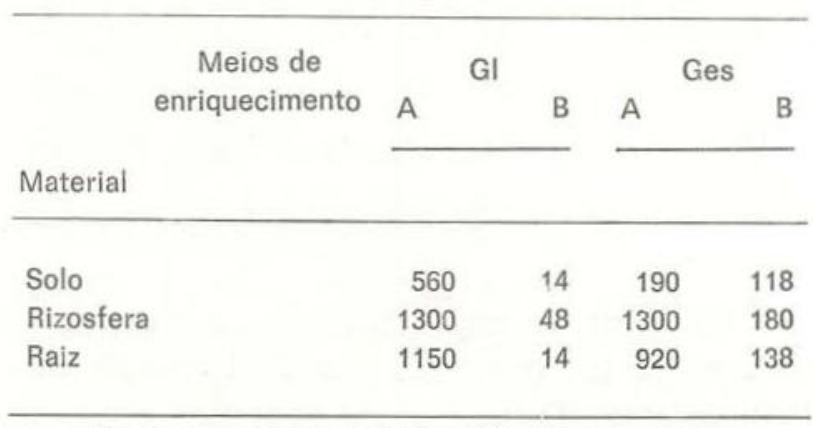

$A=$ Nọ de microrganismos total $\times 104 \times g$ peso seco-1.

$\mathrm{B}=\mathrm{No}$ de bactérios solubilizodoras de fosfato $\times 104 \quad \mathrm{~g}$ peso seco-1.

Apesar do número relativamente alto de bactérias solubilizadoras no solo, detectados principalmente no meio GES (Tabela 3), o levantamento quantitativo destes microrganismos foi feito somente da rizosfera de diferentes gramíneas e leguminosas forrageiras, por ser a rizosfera um sítio adequado para ocorrência e crescimento de microrganismos. Segundo esse levantamento, tanto as leguminosas quanto as gramíneas apresentaram um número maior de bactérias solubilizadoras nos tratamentos com adubação, com exceção de H. rufa, P. maximum, S. guianensis (CIAT 136) e S. capitata (Fig. 1).

De uma maneira geral, os números maiores de solubilizadores de fosfato (superior a $1 \times 10^{7} / \mathrm{g}$ rizosfera) ocorreram nas rizosferas de leguminosas, tanto nas adubadas quanto nas não adubadas, e os números mais baixos nas gramíneas (inferior a $1 \times 10^{7} / \mathrm{g}$ rizosfera) com a exceção de $H$. rufa e $P$. maximum sem adubação. Zornia sp. e $D$. ovalifolium mostraram maiores porcentagens em relação ao total (Tabela 4) e de todas as forrageiras analisadas, a rizosfera de Zornia sp. adubada foi a que melhor se apresentou tanto em número quanto em porcentagem de bactérias solubilizadoras.

O número total de microrganismos foi maior nos tratamentos não adubados para todas as gramíneas analisadas e maior nos tratamentos adubados para todas as leguminosas, com exceção de S. capitata (Fig. 1).

Os fungos não foram considerados uma vez que estavam presentes em quantidade bem pequena. As bactérias solubilizadoras foram isoladas e purificadas para posterior identificação e classificação. 
Discussão

A fertilidade do solo quanto ac fósforo é geralmente atribuída ao teor deste elemento em formas assimiláveis pelas plantas. As fontes de $\mathrm{P}$ disponíveis no solo são provenientes de matéria vegetal, animal e microbiana e de fosfatos iigados a $\mathrm{Ca}, \mathrm{Mg} \mathrm{Fe}$ e $\mathrm{Al}$ (Barea, 1969) que são rapidamente utilizadas pelas plantas ou mineralizadas por atividades micro. biana.

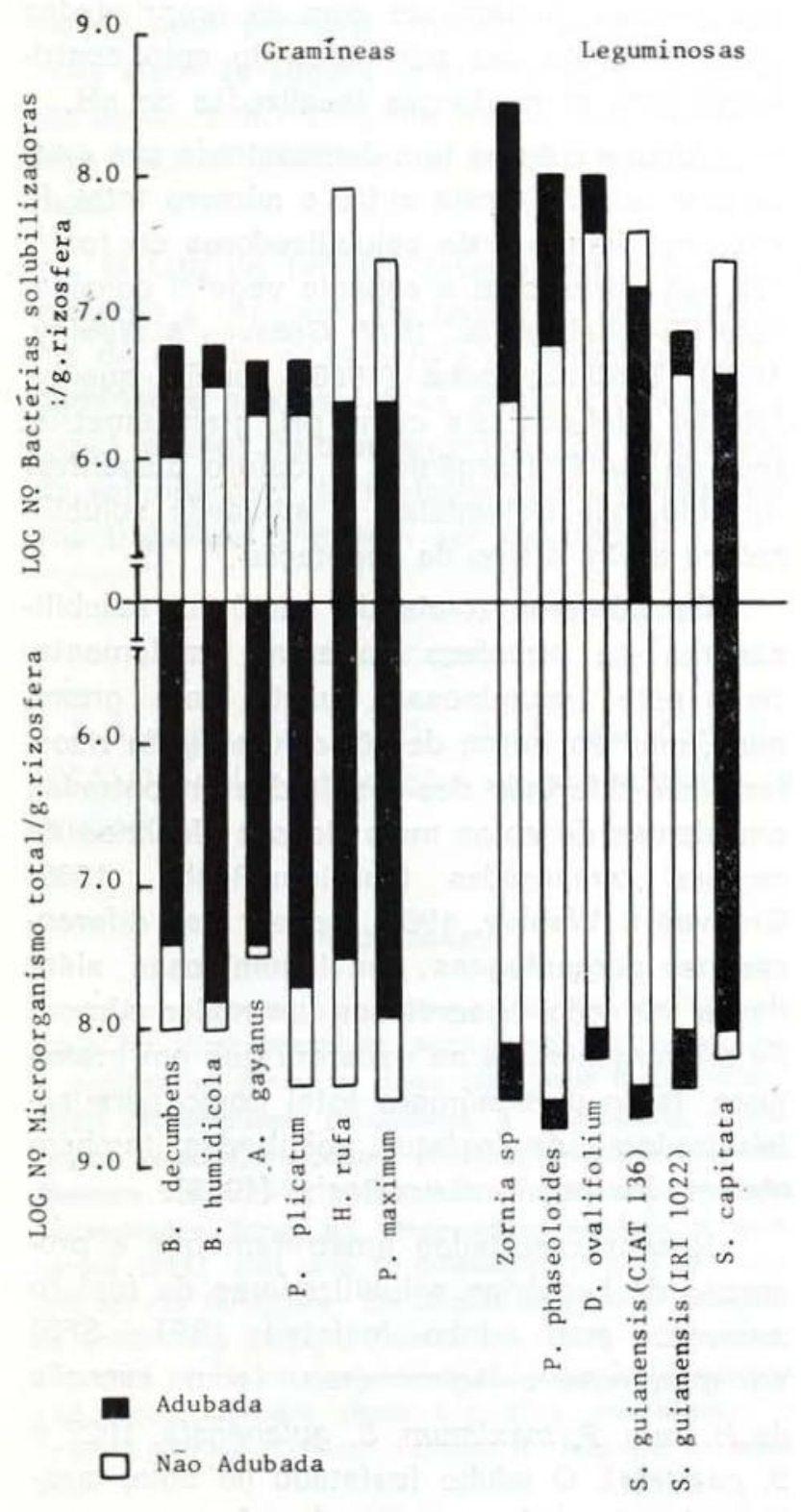

Fig. A - Número total de microrganismos e de bactérias solubilizadoras de fosfatos na rizosfera de gramineas e leguminosas, adubadas e não adubadas.
TABELA $4-$ Porcentagem de bactérias solub:lizadoras de fosfato do número total de microrganismos (média de 3 repetições)

\begin{tabular}{ccc}
\hline Forrageiras & $\begin{array}{c}\text { Adubado } \\
\%\end{array}$ & $\begin{array}{c}\text { Não Adubado } \\
\%\end{array}$ \\
\hline
\end{tabular}

\section{Gramíneas}

$\begin{array}{lrr}\text { Brachiaria decumbens } & 23 & 1 \\ \text { Andropogon gayanus } & 18 & 6 \\ \text { B. humidicola } & 10 & 3 \\ \text { Paspalum plicatum } & 10 & 1 \\ \text { Hyparrhenia rufa } & 8 & 32 \\ \text { Panicum maximum } & 3 & 9\end{array}$

Leguminosas

Zornia sp.

Desmodium ovalifolium

Pueraria phaseoloides

Stylosanthes capitata

S. guianensis (CIAT 136)

S. guianensis (IRI 1022)

O solo do experimento PROPASTO/CIAT em Itacoatiara, em Latossolo Amarelo ácido com textura pesada, possui um teor médio $(130 \mathrm{ppm})$ de fósforo total e um teor baixo (12 $\mathrm{ppm}$ ) de fósforo assimilável, necessitando portanto, de uma intensa atividade microbiana para solubilização dos fosfatos orgânicos e inorgânicos, para manter o fósforo disponível em níveis razoáveis. Gerretsen já em 1948 de. monstrou conclusivamente que plantas absorvem mais fosfatos provenientes de formas insolúveis, quando na presença de microrganismos do solo.

A atividade microbiana, neste traba'ho, foi avaliada indiretamente pela contagem de microrganismos solubilizadores de fosfato na rizosfera de gramíneas e leguminosas.

Rovira (1965) e Katznelson \& Bose (1969), demonstraram que a rizosfera abriga uma grande população de bactérias fisiologicamente mais ativa que os microrganismos não rizosfé. ricos. Esse efeito positivo da rizosfera geralmente traz vantagens, tanto para o crescimento da planta quanto para atividade microbiana. A produção de amino-ácidos, vitaminas e hormônios pelos microrganismos (Lochhead, 1957) assim como a produção de $\mathrm{CO}_{2}$, que resulta na transformação de fosfatos na forma assi. milável é de grande importância para o cresci- 
mento da planta (El-Gibaly et al., 1977). Por outro lado, raízes vivas proporcionam uma contínua e localizada fonte de nutrientes para a microflora do solo através do próprio tecido vivo, exsudato e células mortas (Gray \& Williams, 1971). Até 1965 (Rovira, 1965) já tinham sido identificados, pelo menos, dez açúcares nos exsudato de diferentes plantas, sendo a glicose e frutose geralmente as mais freqüentes e abundantes fontes de carboidratos.

Katznelson \& Bose (1959) estudando a atividade metabólica de bactérias solubilizadoras de fosfatos isolados na rizosfera, rizoplano e solo próximo às raízes de trigo, encontraram uma maior atividade de oxidação de glicose e alanina por bactérias do rizoplano e uma atividade média para as rizosferas e solo. De uma maneira geral, a maioria delas pertencia a um grupo nutricional que requeria uma substância desconhecida presente no caldo de carne e extrato de solo para um ótimo crescimento. Nos ensaios desenvolvidos, foi selecionado um meio que proporcionasse um melhor crescimento para um maior número de microrganismos solubilizadores de fosfatos, e o melhor foi o GES, justamente o que continha glicose, extrato de solo e sais minerais. Esse meio possibilitou maior crescimento de bactérias solubilizadoras apesar de não ter inibido a ocorrência de funços. Nos experimentos realizados neste trabalho e em outros em andamento, encontramos sempre um pequeno número de fungos solubilizadores em relação às bactérias solubilizadoras de fosfatos. No entanto, diferentes trabalhos têm demonstrado a importância dos fungos solubilizadres de fosfatos (Agninotri, 1970; Carvatho et al., 1969; Sethi \& Subba-Rao, 1968; Chhonkar \& Subba-Rao, 1965). Talvez com meios mais apropriados para o desenvolvimento de fungos, esse fato não ocorresse, se bem que mesmo no meio GELP com levedura, em $\mathrm{pH}$ ácido e neutro, na presença ou ausência de rosa-bengala, a ocorrência foi muito pequena. É possível que as bactérias crescendo no meio produzam substâncias que inibem o crescimento dos wungos.

$\mathrm{O} \mathrm{pH}$ dos solos onde as amostras foram coletadas variaram em torno de 4,5 a 5,0 e, em relação ao $\mathrm{pH}$ dos meios, números maiores de bactérias solubilizadoras foram verificados em $\mathrm{pH}$ neutro. Geralmente bactérias e actinomicetos dos solos são menos tolerante à condição de acidez do que fungos, mas a sua ocorrência dentro de uma fáixa de $\mathrm{pH}$ no solo não significa que esteja vivendo e realizando todas as suas atividades nesse $\mathrm{pH}$ (Gray \& Williams, 1971). Ainda de acordo com esses autores, a reação de um micro-ambiente não é sempre a mesma dos macro-ambientes, onde a atividade dos organismos do solo e raízes das plantas, juntamente com as propriedades químico-físicos das partículas do solo contribuem para as mudanças localizadas de $\mathrm{pH}$.

Alguns autores têm demonstrado que existe uma relação direta entre o número total de microrganismos e de solubilizadores de fosfatos nas raízes com a espécie vegetal considerada (El-Gibaly et al., 1977; Greaves \& Webley, 1965). Tardieux-Roche (1966) conclui que os fatores edáficos tais como $\mathrm{pH}$, granulometria, teor de matéria orgânica e fósforo disponivel no solo, não influenciam a atividade solubilizadora e sim o tipo de vegetação.

Os números totais de bactérias solubilizadoras na rizosfera variaram amplamente, tanto para leguminosas quanto para gramineas, mas em torno de $10^{6}$ células $/ \mathrm{g}$ de rizosfera, não diferindo dos resultados encontrados em plantas de solos mais ricos e alcalinos de regiões temperadas (Tardieux-Roche, 1966; Greaves \& Webley, 1965), apesar das diferenças nas porcentagens. Em leguminosas além dessa variação, observamos um maior número de microrganismos na rizosfera que em gramíneas, tanto para número total como para solubilizadores de fosfatos, resultados também observados por Tardieux-Roche (1966).

Nossos resultados mostraram que a proporção de bactérias solubilizadoras de fosfato aumentou com adubo fosfatado (SFT + SFS) em gramíneas e leguminosas, (com exceção de $H$. rufa, P. maximum, S. guianensis, $1022 \mathrm{e}$ S. capitata). $\mathrm{O}$ adubo fosfatado no solo, mesmo aplicado na forma solúvel, sofre processos de fixação. Talvez os microrganismos que solubilizem o fósforo tenham uma vantagem na competição com os outros microrganismos. 
O número total de microrganismos em gramíneas foi maior em solos não adubados, o que talvez indique uma melhor interação destes microrganismos com gramíneas em condições naturais. Pode ser que a quantidade e a qualidade dos exsudatos de raízes dessas gramíneas tenham sido diferentes das gramí. neas adubadas.

Em leguminosas foi encontrado maior número de microrganismos e solubilizadores de fosfato em solos adubados. Nesse caso, a adubação poderia ter influido nos exsudatos das raízes num processo inverso ao das gramíneas além de sugerir uma interação do adubo fosfatado com nit ogênio fixado nes nódulos, para melhor crescimento desses microrganismos.

O fato de termos determinado quantitativamente a presença de bactérias solubilizadoras de fosfato na rizosfera de gramíneas e leguminosas não esclarece ainda a função e o papel desses microrganismos nos processos de solubilização de fosfatos neste sertido novos trabalhos precisam ser realizados.

\section{Agradecimento}

Agradecemos ao Dr. Paulo de Carvalho (ESALQ) pela introdução na metodoiogia e orientação.

\section{SUMMARY}

After choosing a selective enrichment medium suitable for most phosphate solubilizing microorganisms, a quantitative survey of these was made in the rhizosphere of: Brachiaria decumbens, B. humidicola, Andropogon gayanus, Paspalum plicatum, Hyparrhenia rufa, Panicum maximum, Desmodium ovalifolium, Pueraria phaseoloides, Zornia sp., Stylosanthes capitata, S. guianensis (CIAT 136), and S. guianensis (IKE 1022, with and without fertilisers. The largest numbers of phosphate solubilizing bacteria (above $1 \times 10^{7} / \mathrm{g}$ rhizosphere) occurred in the rhizosphere of the leguminous species and small numbers (Belw $1 \times 10^{7} / \mathrm{g}$ rhizosphere) in grasses without fertilisers, except $\mathbf{H}$. rufa and $\mathbf{P}$. maximum.

From all the fodder plants analysed, Zornia sp. (Leguminosae) with fertilizer, had the greatest number as phosphate solubilizers. The total number of microorganisms was greater in the treatments without fertilizer in all grasses analysed; but for the leguminous species it was greater for treatments with fertilizer except in S. capitata. Phosphore solubilizing fungi were not considered in this study because they present only in small numbers.

\section{REFERENCIAS BIBLIOGRAFICAS}

AGNIHOTRI, V.P.

1970 - Solubilization of insoluble phosphates by some soil fungi isolated from nursery seebeds. Can. J. Microbiol., 16: $877-880$.

BAREA, J.M.

1969 - Estudio sobre germenes del suelo capaces de mineralizar los fosfatos orgânicos. I Introduccion y revision bibliográfica. Avs. Pharm. X 177: 177-128.

BAREA, J.M.; NAVARRO, E. \& MONTOYA, E.

1976 - Prodution of plant growth regulators by rhizosphere phosphate solubilizing bacteria. J. appl. Bact., 40: 129-134.

BROWN, M.E.

1974 - Seed and root bacterization. Ann. Rw. Phytopathol., 12: 181-197.

CARVAlHO, P.C.T. de; EIRA, A.F. da; PELlegrino, D.

1969 - Solubilização quantitativa de fosfatos insolúveis, por algumas espécies dos gêneros Aspergillus e Penicillium. Anais da E.S.A. “Luiz de Queiroz", 26: 173-185.

CHHONKAR, P.K. \& SUBBA-RAO, N.S.

1965 - Phosphate solubilization by fungi associated with legume root nodules. Can. J. Microbiol., 13: 749-753.

EL-GIBALY, M.H.; EL-REWEINY, F.M.; ABDEL-NASSER, M. \& EL-DAHTORY, Th.A.

1977 - Studies on phosphate-solubilizing bacteria in soil and rhizosphere of different plants. I Occurrence of bacteria, acid producers and phosphate dissolvers. Zbl. Bakt. II., 132: 245-250.

EPSTEIN, E.

1975 - Nutrição mineral das plantas: princípios e perspectivas. Rio de Janeiro, Livros Técnicos e Científicos. 341p.

FASSBENDER, H.W.

1975 - Química de suelos con enfasis en suelos de America Latina I. Turrialba, Ed. Turrialba, IICA. 398p.

GERRETSEN, F.C.

1948 - The influence of microorganisms on the phosphate intake by the plant. Plant and soil., 1 (1): 51-81.

GRAY, T.R.C. \& WILLIAMS, S.T.

1971 - Soil microorganisms. London, Longman Group Limited. 240p. 
GREZVES, M.P. \& WEBLEY, D.M.

1965 - A study of the breakdown of organic phosphates by microorganisms from the root region of certain pastures grasses. J. appl. Bacter., 28 (3): 454-465.

KAMPRATH, E.J.

1977 - Phosphores. In: Sanchez, P.A., ed. A Review of Soil Research in Tropical Latin America. North Canolina Sstate University Tech. Bul., (219): 1-197.

KATZNELSON, H. \& BOSE, B.

1959 - Metabolic activity and phosphate-dissolving capability by of bacterial isolates from wheat roots, rhizosphere and non rizosphere soil. Can. J. Microbiol., 5: 79-85.

LOCHKEAD, A.G.

1957 - Qualitative studies of soil microorganisms. $X V$. Capability of the predominant bacterial flora for synthesie of varions growth factors. Soil Sci., 84: 395-403.
RAMOS, A.; CALLAO, V. \& CARVALHO, P.C.T. de.

1968 - La solubilizacion de fosfatos por hongos del suelo. Microbiol. Españ., 21: 23-37.

ROVIRA, A.D.

1965 - Plant root exudates and their influence upon soil microorganisms. In: Baker, K.F. and Snyder, W.C. eds. Ecology of soil borne plant pathogens. Prelude to biological control. London, Albermale Street, p. 170186.

SETHI, R.P. \& SUBBA-RAO, N.S.

1968 - Solubilization of tricalcium phosphate and calcium phytate by soil fungi. J. Gen. Appl. Microbiol., 14: 329-331.

SPERBER, J.I.

1958 - The incidence of apatite-solubilizing organisms in the rizosphere and soil. Anst. J. Agric. Res., 9 (6): 778-781.

TARDIEUX-ROCHE, A

1966 - Contribution a l'etude des interactions entre phosphates naturels et microflore du sol. Ann. agron., 17 (4): 403-471.

(Aceito para publicaçăo em $17 / 07 / 81$ ) 